\title{
KOMPETENCIJE FIZIOTERAPEUTA U SUVREMENOM ZDRAVSTVENOM SUSTAVU
}

\author{
Dragan Mijatović ${ }^{1}$, Antonija Hrkać ${ }^{1}$, Mate Brekalo ${ }^{2}$ \\ ${ }^{1}$ Fakultet zdravstvenih studija, Sveučilište u Mostaru, BiH \\ ${ }^{2}$ Fakultet prirodoslovno-matematičkih i odgojnih znanosti, Sveučilište u Mostaru, BiH \\ Rad je primljen 11.09.2018. Rad je recenziran 19.9.2018. Rad je prihvaćen 27.9.2018
}

\section{SAŽETAK:}

UVOD: Fizioterapeuti 21. stoljeća su zdravstveni stručnjaci koji su završili studij fizioterapije i koji su osposobljeni i kvalificirani za sudjelovanje u postupcima procjene bolesnika, izradi plana terapije i provođenje istoga kao i veliku ulogu u prevenciji te procjeni učinka terapije. CILJ: Cilj ovog članka je opisati kompetencije fizioterapeuta u suvremenom zdravstvenom sustavu te se osvrnuti na međunarodne standarde i preporuke o radu istih te standarde svjetske i europske konfederacije fizioterapeuta WCPT i ERWCPT.

METODE: Provedena je elektronska pretraga baze podataka PubMed-a, EBSCO-a te pretraga u bazi Google Znalac. Pretraga je obavljena koristeći ključne riječi u razdoblju od zadnjih deset godina a naglasak je bio na istraživanja koja obrađuju kompetencije fizioterapeuta u suvremenom zdravstvenom sustavu.

REZULTATI: Iz radova koji su analizirani može se vidjeti da obrazovni sustavi još uvijek nisu dostatni da bi pratili niz preporuka od WCPT kao i ER-WCPT. Teži se ka tome da fizioterapeut može napraviti informiranu kliničku prosudbu o tome treba li klijenta ili pacijenta zadržati ili uputiti na drugog profesionalca koji se odnosi na jedno ili više područja specijalnosti.

ZAKLJUČAK: Prepoznavanje kompetencija fizioterapeuta, njihovo vrednovanje kao i utvrđivanje kompetencija koje fizioterapeuti nemaju bitno je za uspješnost u njihovom radu. Ključne riječi: physiotherapy, professional competence, physiotherapist education, standards.

Osoba za razmjenu informacija:

Dragan Mijatović

E mail mijatovicdragan@ymail.com

\section{UVOD}

Za fizioterapeute se može reći da su zdravstveni stručnjaci koji su završili studij fizioterapije i koji su osposobljeni da upravljaju procesima fizioterapije. Temeljna edukacija terapeuta je studij fizioterapije kroz koji je terapeut osposobljen i kvalificiran za sudjelovanje u postupcima procjene bolesnika, izradi plana terapije i provođenje istoga kao i veliku ulogu u prevenciji te procjeni učinka terapije. Može se reći da ne postoji kliničko područje gdje se ne primjenjuje fizioterapija kojoj je glavni cilj očuvanje, razvoj ili ponovno uspostavljanje optimalne tjelesne funkcije. Kvalitetna edukacija je ključna za kompetencije koje terapeut stječe. Do sada u visokom školstvu nije posvećeno previše pozornosti o kompetencijama niti kako se one poimaju u samome obrazovanju. Kompetencije bi se mogle promatrati kroz četiri opisne kategorije - "savladavanje osnovnih vještina, razumijevanje teorijske osnove fizioterapije, holistički pogled na fizioterapiju, uključivanje i razvoj višeprofesionalne suradnje". Studenti koji su završili studij imali su različite i široke predodžbe o tome što kompetencija u fizioterapiji podrazumijeva i što pokriva njihova vlastita kompetencija (1).

Proučavajući kompetencije može se postaviti pitanje jesu li iste dovoljne u različitim uvjetima pri raspolaganju različitim resursima. Napravljeno je istraživanje gdje su kanadski fizioterapeuti radili u zemljama sa oskudnim resursima. Ustanovilo se da 
kompetencije koje su stekli nisu bile dostatne te se zaključilo da se one moraju dodatno proširiti (2).

Specifičnost posla fizioterapeuta koji zahtjeva i određeni stupanj emocionalne kompetencije, pogotovu kod fizioterapeuta koji će u budućnosti sudjelovati u nastavnom progamu pokazuje i istraživanje provedeno u Wrocławu, Poljska. Osposobljavanje usmjereno na razvijanje profesionalnih i socijalnih emocionalnih vještina je potrebno, posebno u zanimanjima zasnovanim na tijesnim međuljudskim odnosima (3). Stoga, u pripremi kandidata za buduće učitelje i fizioterapeute, bitno je da pored činjeničnih znanja i vještina također se usredotoči na razvoj osobnih kvaliteta i društvenih i emocionalnih kompetencija. Ovaj sfera je vrlo zanemarena na poljskim sveučilištima, gdje se izvode posebne nastave koje razvijaju interpersonalne vještine studenata samo povremeno (4). Globalne zdravstvene kompetencije bile su pitanje istraživanja provedenog u sveučilištu Texas u El Pasu. Ukazano je na potrebu revizije kompetencija kako bi bile više relevantne za fizioterapeutsko obrazovanje, odnosno na koji način najučinkovitije priprema studente fizioterapeuta za kompetentnu praksu u globaliziranom svijetu (5). Kliničko obrazovanje (također nazvano "klinički nadzor") bitno je za obuku na studijima fizioterapije. Fizioterapeuti koji su prošli kliničko obrazovanje imaju ključnu ulogu u olakšavanju učenja i procjene uspješnosti studenata, no istraživanje sugerira da mnogi preuzmu tu ulogu zbog spremnosti, dostupnosti ili očekivanja, a ne vještina ili iskustva (6).

Cilj ovog članka je opisati kompetencije fizioterapeuta u suvremenom zdravstvenom sustavu te se osvrnuti na međunarodne standarde i preporuke o radu istih te standarde svjetske i europske konfederacije fizioterapeuta WCPT i ERWCPT.

\section{MATERIJALI I METODE}

Ovaj rad je pregledni i uključuje analizu i kritičke osvrte radova pronađenih $\mathrm{u}$ elektronskim bazama podataka. Napravljena je pretraga elektronske baze podataka PubMed-a te EBSCO-a a pretražena je i baza Google Znalac. Pretraga je rađena unošenjem ključnih riječi: physiotherapy, professional competence, physiotherapist education, standards.
Izdvojeni su radovi vezani za edukaciju i kompetenciju fizioterapeuta. Radovi su izdvojeni na osnovu sažetaka.

Kao kriterij isključenja uzeta je činjenica da radovi moraju biti takvi da obrađuju kompetenciju fizioterapeuta u postupcima procjene bolesnika, izradi plana terapije i provođenje istoga. Pretraga baze podataka izvodila se u razdoblju od 07.05 - 15.05.2018 od strane tri pretraživača (D.M., A.H., M.B.). Što se ograničenja za vremensko razdoblje tiče, uzeto je u obzir razdoblje od deset godina. Na kraju filtriranja radova na osnovu kriterija isključenja u obzir je uzeto 19 radova. Oni su detaljnije obrađeni te se na osnovu toga donio zaključak.

\section{RASPRAVA}

Kompetencije fizioterapeuta tema su oko koje se uvelike raspravlja diljem svijeta. Napredni fizioterapeut je fizioterapeut koji je formalno pokazao sposobnost primjene naprednih kompetencija (znanja, vještina i stavova) u određenom području, u okviru prakse priznate kao fizikalna terapija; posjeduje visoko specijalizirane vještine za donošenje složenih odluka i upravljanje rizikom u nepredvidivim situacijama, koje zahtijevaju inovacije; završio je napredni program i može demonstrirati da on može raditi na naprednom nivou, s naglaskom na određenom području kliničke prakse, obrazovanja, istraživanja, odnosno profesionalnom upravljanju (7). Prema međunarodnom standardu koji je pripremljen $\mathrm{u}$ skladu s Uredbom Komisije (EK) br. 1022/2009 od 29. listopada 2009. o izmjenama i dopunama Uredbe (EK) br. 1738/2005, Uredbe (EK) br. 698/2006 i Uredbe (EK) br. 377/2008 o Međunarodnoj standardnoj klasifikaciji zanimanja (ISCO), te Preporuke Komisije (EK) br. 824/2009 od 29. listopada 2009. o primjeni Međunarodne standardne klasifikacije zanimanja (ISCO-08) opisano je zvanje fizioterapet. $S$ navedenim dokumentima se uskladila i Republika Hrvatska te je Zavod za statistiku RH istu klasifikaciju objavio u Narodnim novinama, broj 147/10. i opširno ju publicirao (Fizioterapeuti/fizioterapeutkinje - šifra 2264):

Fizioterapeuti/fizioterapeutkinje procjenjuju, planiraju i provode rehabilitacijske programe kojima se 
poboljšavaju ili oporavljaju ljudske motoričke funkcije, povećava sposobnost pokreta/kretanja, ublažava bol te liječi ili sprječava tjelesne poteškoće povezane s ozljedama, bolestima i drugim oštećenjima. Služe se različitim fizioterapijskim vještinama i tehnikama kao što su pokret/kretanje, ultrazvuk, primjena toplinskih modaliteta, laser i druge metode.

Poslovi koje obavljaju uključuju:

- provođenje testova pokretljivosti mišića, živaca, zglobova i funkcionalne sposobnosti radi utvrđivanja i procjene tjelesnih problema pacijenata,

- određivanje ciljeva liječenja s pacijentima i osmišljavanje programa liječenja radi smanjenja tjelesnoga bola, ojačavanja mišića, poboljšanja kardiotorakalnih, kardiovaskularnih i respiratornih funkcija, vraćanja pokretljivosti zglobova te poboljšanja ravnoteže i koordinacije,

- planiranje, provođenje i nadzor programa liječenja primjenom terapijskih vježbi, topline, hladnoće, masaže, manipulativnih tehnika, hidroterapije, elektroterapije, ultraljubičastih i infracrvenih zraka te ultrazvuka pri liječenju pacijenata,

- upućivanje pacijenta i njegove obitelji u postupke koje trebaju nastaviti provoditi izvan kliničkoga okruženja,

- bilježenje podataka o zdravstvenome stanju pacijenata i reakcijama na liječenje u bazama podataka o pacijentima te razmjena tih podataka $s$ drugim zdravstvenim stručnjacima radi nastavka cjelokupne njege,

- planiranje i provođenje programa za praćenje i sprječavanje uobičajenih tjelesnih poteškoća i poremećaja,

- nadzor nad radom fizioterapeutskih pomoćnika i drugih (8-10).

Prema Europskoj regiji Svjetske konfederacije za fizikalnu terapiju / fizioterapiju (Regulirano u $26 \mathrm{dr}$ žava članica EU i u zemljama EFTA-e) fizioterapeuti su autonomni zdravstveni djelatnici koji su odgovorni za razvoj, održavanje ili obnavljanje motoričke funkcije i kretanja tijekom cijelog životnog vijeka pomoću prakse utemeljene na dokazima. Oni oslobađaju bol i liječe ili sprečavaju fizičke uvjete povezane s ozljedama, bolestima ili drugim oštećenjima. Fizioterapeuti osnažuju bolesnike i njihove skrbnike da upravljaju stanju izvan kliničkih postavki. Oni rade u okviru svoje prakse i njihovog profesionalnog Kodeksa ponašanja. Napredni fizioterapeuti su visoko specijalizirani. Oni donose složene odluke i upravljaju rizicima u nepredvidljivim kontekstima i unutar određenog područja. Oni se mogu usredotočiti na određeno područje kliničke prakse, obrazovanja, istraživanja ili profesionalnog upravljanja. Pomoćnik fizioterapeuta - pomoćnici fizioterapeuta rade pod nadzorom, unutar definiranih konteksta korištenjem dogovorenih protokola liječenja i postupaka kao što su prikupljanje podataka o klijentima i održavanje potrebne opreme u fizioterapijskim intervencijama. Ukupnu odgovornost zadržava delegirajući stručnjak.

Prema Svjetskoj konfederaciji za fizikalnu terapijufizioterapeuti su kvalificirani i profesionalno dužni:

- poduzeti sveobuhvatan pregled / procjenu pacijenta / klijenta ili potrebe skupine klijenata,

- procijeniti nalaz iz pregleda / procjene kako bi se načinile kliničke prosudbe o pacijentima / klijentima,

- formulirati dijagnozu, prognozu i plan

- pružiti konzultacije u okviru svoje stručnosti i utvrditi kada pacijenti / klijenti moraju biti upućeni drugom zdravstvenom radniku

- provesti terapijski program za intervenciju / liječenje

- odrediti ishode svih intervencija / tretmana

- dati preporuke za samopomoć.

Jesu li kompetencije terapeuta adekvatne odnosno dostatne dio je istraživanja koja se provode u mnogim zemljama. Istraživanje koje je provedeno u Njemačkoj imalo je za cilj istražiti jesu li nastavni planovi i programi za obrazovanje fizioterapije u Njemačkoj sukladni standardima preporučenim u Svjetskoj konfederaciji za fizikalnu terapiju (WCPT) smjernice za profesionalni stupanj obrazovanja fizioterapeuta, objavljenog od strane WCPT-a. Zaključeno je da niti jedan od njemačkih obrazovnih standarda ne zadovoljava očekivanja WCPT (11). $S$ druge strane u Sloveniji je provedeno istraživanje kojem je cilj bio dokazati da terapeuti u Sloveniji imaju potrebna znanja, vještine u provedbi prakse utemeljene na dokazima. Istraživanje je ukazalo na 
mnoge poteškoće (12). Istraživanje provedeno od Adam K i suradnika odnosilo se na rano zapošljavanje okupacionih terapeuta (OT) i fizioterapeuta (PT) u tretiranju i prevenciji ozljeda u Australiji. Poslodavci su izrazili zabrinutost zbog nespremnosti ranih diplomanata u tretiranju i prevenciji ozljeda na radu. Nažalost, istraživanje pokazuje da studenti koji su tek završili sa studiranjem nisu još spremni da praktično tretiraju povrede i da sudjeluju u prevenciji istih (13). Istraživanje provedeno u Poljskoj, od strane Włoszczak-Szubzda A. i Jarosz M. ukazuje na nedostatke komunikacijske kompetencije fizioterapeuta na temelju obrazovanja na području opće psihologije i opće međuljudske komunikacije. Komunikacijske kompetencije stečene tijekom dodiplomskog obrazovanja fizioterapije podložne su regresiji tijekom profesionalne aktivnosti (14). U Nizozemskoj je 2006. godine provedeno istraživanje gdje se promatrao direktan pristup pacijenata fizioterapeutima. Naime, u Nizozemskoj je u 2006. godini uveden je direktan pristup fizioterapiji bez potrebe o upučivanjem od strane liječnika. U usporedbi sa prethodnom godinom nije bilo povećanog direktnog pristupa pacijenata fizioterapiji u odnosu na dotadašnji protokol, dakle nakon upute od strane liječnika (15). Međutim, zaključak ovog istraživanja ne možemo ozbiljnije shvatiti jer je provedeno iste godine nakon promjene sustava pristupa fizioterapiji. Bitnost etičke kompetencije naglašena je u radu Gard G. i suradnika u Danskoj. Naglasak je bio na četiri deskriptivne teme: opća razmišljanja o etici u fizioterapiji; važnost prve fizioterapijske sesije; učinak kliničkog okruženja na prvu sesiju; razmišljanja i djelovanja na dobrobit prema pacijentu u prvoj sesiji. Dobrobit prema pacijentu temeljni je aspekt fizioterapeutovog razumijevanja prve sesije. Međutim, ako fizioterapeuti nemaju dublju etičku svijest, fizioterapeut može razmišljati i / ili djelovati etički u različitoj mjeri: samo će etički svjestan fizioterapeuta znati kada reflektira i djeluje etički. Preporučljivo je daljnje istraživanje etičkih problema u privatnoj praksi i svjesno usredotočenje na stjecanje znanja o tome kako prepoznati, analizirati i riješiti etička pitanja kako bi se pridržavali očekivanja društva i zahtjeva profesionalne kompetencije fizioterapeuta, kao i etičkih kompetencija (16). Istraživanje provedeno od Ramirez-Velez R. i suradnika u Kolumbiji naglašava pozitivnost studenata fizioterapije naspram stavova prema praksi utemeljenoj na dokazima te da su zainteresirani za učenje ili poboljšanje vještina potrebnih za usvajanje iste. Nedostatak istraživačkih vještina, učenje o metodologiji i statistici su otkrivene kao neke od glavnih prepreka za implementaciju prakse utemeljene na dokazima (17). Fizioterapija bi trebala razmišljati drugačije o obrazovanju na početnoj razini, fokus na znanje i kompetencije, koji je bio glavni oslonac u fizioterapijskom obrazovanju, mora se sada shvatiti u kontekstu obrazovanja koje obuhvaća znanje, rad i život (18). Bitna smjernica WCPT-a određuje standarde obrazovanja za fizioterapeute koji mogu djelovati kao samostalni praktikanti, bez upućivanja od drugog zdravstvenog radnika. Zadržati ili uputiti pacijenta dalje je sastavni dio nacionalnih smjernica za fizioterapijsku profesiju zemalja članica Europske mreže fizioterapije u visokom obrazovanju, ENPHE (19). Suvremene definicije fizikalne terapije podupiru struku koja ima vodeću ulogu u sprječavanju, preusmjeravanju i upravljanju životnim stilovima. Usredotočenje na kliničke sposobnosti povezane $s$ učinkovitim obrazovanjem u zdravstvu i promjenama ponašanja u zdravstvu prioriteti su za budućnost (20). Praksa fizikalne terapije 21. stoljeća zasnovana je na znanstvenim dokazima. Fizikalna terapija mora biti rješenje suvremenih zdravstvenih poteškoća. Epidemiološki podaci kombinirani s dokazima koji podupiru djelotvornost neinvazivnih intervencija vezanih uz fizikalnu terapiju u svrhu rješavanja tih prioriteta (npr. Zdravstvenog odgoja i vježbanja) vrlo su konzistentni s promicanjem zdravlja i wellnessa i ICF-a. Ovaj dokaz proizlazi iz definicije zdravlja od strane Svjetske zdravstvene organizacije (WHO) i Međunarodne klasifikacije funkcioniranja (ICF), WHO i drugih međunarodnih baza podataka o prevalenciji životnih uvjeta. S obzirom na njihovu predanost iskorištavanju učinkovitih neinvazivnih intervencija, fizioterapeuti su u pretežnoj poziciji da se usredotoče na prevenciju tih onesposobljavajućih i smrtonosnih stanja u svakom klijentu ili pacijentu, njihovom liječenju u nekim slučajevima, kao i 
njihovom upravljanju (21). Sukladno suvremenoj definiciji fizikalne terapije, prakse, stručnog obrazovanja $i$ istraživanja, fizikalna terapija treba odražavati zdravstvene prioritete 21 . stoljeća i uskladiti se s globalnim i regionalnim strategijama javnog zdravstva. Predloženi fokus na zdravlje naglašava kliničke sposobnosti, uključujući procjenu zdravstvenih, zdravstvenih ponašanja načina života i faktora rizika za životni stil; i propisivanje intervencija za promicanje zdravlja i dobrobiti u svakom klijentu ili pacijentu. Takav pristup ima za cilj povećati prag za kronične uvjete tijekom životnog ciklusa i smanjiti njihovu stopu progresije, čime se sprječava, odgađa ili smanjuje ozbiljnost bolesti i invaliditeta. Fizioterapeut 21. stoljeća mora biti sposoban vježbati ovakve sposobnosti u kontekstu kulturološkog različitog društva kako bi učinio pozitivnu promjenu ponašanja u zdravstvu (22). Naglasak je na potrebi da udruženi zdravstveni stručnjaci trebaju razviti specifične kliničke standarde prakse, restrukturirati modele pružanja zdravstvene skrbi kako bi se olakšala obuka, nastaviti razvijati bazu podataka utemeljenu na dokazima te ocijeniti učinkovitost obuke kako bi se postigla neovisnost u praksi. Davatelji zdravstvenih usluga, dakle fizioterapeuti, moraju surađivati sa sveučilištima, sektorom strukovnog obrazovanja i vladom kako bi optimizirala sposobnost donošenja odluka vezanih za skrb o pacijentima (23). Vizija 2020 poslužila je kao vizija za fizioterapijsku profesiju od njezinog usvajanja od strane APTA (America Physical Therapy association), House of Delegates (House) iz 2000. godine, sve dok House 2013 nije usvojio trenutnu izjavu o viziji za profesionalnu fizikalnu terapiju. Fizioterapiju će do 2020. godine pružati fizioterapeuti koji su doktori fizioterapije, priznati od strane pacijenata i drugih stručnjaka zdravstvene skrbi kao praktičari izbora kod kojih pacijenti imaju izravan pristup dijagnostici, intervencijama i prevenciji oštećenja. Doktorima fizioterapije pomagati će fizioterapeutski asistenti koji su obrazovani i licencirani za pružanje fizioterapeutskih intervencija koje su usmjerene i nadzirane (24).

\section{Ograničenje istraživanja}

Potencijalno ograničenje ovog istraživanja je nedostatan broj istraživanja koja su provedena na temu kompetencija fizioterapeuta kao samostalnih zdravstvenih stručnjaka, s naglaskom da su provedena istraživanja istraživala mogućnost samostalnog rada fizioterapeuta sa kompetencijama prvog ciklusa obrazovanja.

\section{ZAKLJUČAK}

Kompetencije terapeuta trebaju biti takve da on može djelovati kao samostalan stručnjak. Kompetencije mogu odražavati jake strane studenata fizioterapije, s druge strane mogu istaknuti slabe kompetencije fizioterapeuta koje se mogu koristiti za poboljšanje edukacije fizioterapeuta. Iz radova koji su analizirani može se vidjeti da obrazovni sustavi još uvijek nisu dostatni da bi pratili niz preporuka od WCPT kao i ER-WCPT nakon prvog ciklusa obrazovanja. Teži se ka tome da fizioterapeut može napraviti informiranu kliničku prosudbu o tome treba li klijenta ili pacijenta zadržati ili uputiti na drugog profesionalca koji se odnosi na jedno ili više područja specijalnosti. Kvalitetno educirani fizioterapeuti su zdravstveni stručnjaci sposobni da naprave kvalitetnu dijagnostiku korištenjem specifičnih koncepata te na osnovu te dijagnostike da načine plan rehabilitacije i isti kvalitetno provedu. Kompetencije terapeuta usko su povezane sa kvalitetom edukacije kroz koju su prošli. Kvalitetno educiran terapeut sigurno je vrhunski zdravstveni stručnjak spreman da odgovori na zahtjeve moderne medicine, da bude dovoljan samokritičan, te da prepusti probleme koje nije kadar samostalno rješiti drugim stručnjacima.

\section{LITERATURA:}

1. Kurunsaari M, Tynjälä P, Piirainen A. Graduating Physiotherapy Students' Conceptions of Their Own Competence. Vocations And Learning. 2018;11(1):1-18.

2. Cassady C, Meru R, Chan N, Engelhardt J, Fraser M, Nixon S. Physiotherapy beyond Our Borders: Investigating Ideal Competencies for Canadian Physiotherapists Working in Resource-Poor Co- 
untries. Physiotherapy Canada. 2018;66(1):1523.

3. Romanowska-Tołłoczko A. Emotional competencies of the forthcoming physiotherapists and physical education teachers. Physical Education Of Students. 2014;(18):70-3.

4. Romanowska-Tołłoczko A, Miedzińska B. Pedagogical and psychological pre-service teacher training in different types of higher education institutions. Medical-Biological Problems of Physical Training and Sports. 2012;(6):119-23.

5. Pechak C, Black J. Global Health Competencies for Physiotherapist Education in the United States. Physiotherapy Research International. 2018;21(3):188-98.

6. Newstead C, Johnston C, Nisbet G, McAllister L. Physiotherapy clinical education in Australia: Development anc validation of a survey instrument to profile clinical educator characteristics, experience and training requirements. New Zealand Journal Of Physiotherapy. 2017;45(3):15469.

7. [Internet] Narodne novine. Zakon o fizioterapeutskoj djelatnosti. Internet. Dostupno na: https://narodne-novine.nn.hr/clanci/sluzbeni/2008_10_120_3437.html. (Datum zadnjeg pristupa: 31.10 .2018 .)

8. [Internet] International Standard Classification of Occupations 2008 (ISCO-08). Documents Of The International Labour Organization. 2011. Internet. Dostupno na: http://www.hkf.hr/LinkClick.aspx? fileticket $=$ qZbDEbaW4Rs\%3d \&tabid=116. (Datum zadnjeg pristupa: 31.10 .2018 .)

9. [Internet] Commission recommendation on the use of the International Standard Classification of Occupations (ISCO-08). 2009.Internet. Dostupno na: http://www.hkf.hr/LinkClick.aspx?fileticket=t1ZtIx9u8UI\%3d\&tabid=116. (Datum zadnjeg pristupa:31.10. 2018.)

10. [Internet] Commission regulation (EC) No 1022/2009 amending Regulations (EC) No 1738/2005, (EC) No 698/2006 and (EC) No $377 / 2008$ as regards the International Standard Classification of Occupations (ISCO). 2009. Internet. Dostupno na: http://www.hkf.hr/
LinkClick.aspx?fileticket=Xdh1Etf8eZc\%3d\&tabid=116. (Datum zadnjeg pristupa: 31.10 .2018 .).

11. Konrad R, Konrad A, Geraedts M. Physiotherapy Education in Germany: Ready for Direct Access? Gesundheitswesen. 2017;79(7):48-55.

12. Hlebš S. Evidence-based practices in physiotherapy. RUO: Revija Za Univerzalno Odlicnost. 2017;6(1):86.

13. Adam K, Strong J, Chipchase L. Readiness for work injury management and prevention: important attributes for early graduate occupational therapists and physiotherapists. Work. 2014;48(4):567-78.

14. Włoszczak-Szubzda A, Jarosz M. Professional communication competences of physiotherapists - Practice and educational perspectives. Annals Of Agricultural And Environmental Medicine. 2013;20(1):189-94.

15. Leemrijse CJ, Swinkels IC, Veenhof C. Direct access to physical therapy in the Netherlands: results from the first year in community-based physical therapy. Physical Therapy. 2008;88:93646.

16. Gard G, Praestegaard J, Gard G. The perceptions of danish physiotherapists on the ethical issues related to the physiotherapist-patient relationship during the first session: a phenomenological approach. Bmc Medical Ethics. 12.

17. Ramirez-Velez R, Correa-Bautista J, Caridad Bagur-Calafat M, et al. Evidence-Based practice: Beliefs, attitudes, Knowledge, and Skills among Colombian physical therapists. Colombia Medica. 2015;46(1):33-40.

18. Alexander KM, Olsen J, Seiger C, Peterson TS. Student Physical Therapists' Competence and Self-Confidence in Basic Clinical Assessment and Musculoskeletal Differential Diagnosis. J Allied Health. 2016;45(2):95-100.

19. Lackenbauer W, Selfe J, Janssen J, Roddam H. Keep/refer decision making abilities of European final year undergraduate physiotherapy students: a cross-sectional survey using clinical vignettes. European Journal Of Physiotherapy. 2017;1-7.

20.Dean E, Al-Obaidi S, De Andrade AD, Gosselink R, Umerah G, Al-Abdelwahab S et all. The First 
Physical Therapy Summit on Global Health: implications and recommendations for the 21 st century. Physiother Theory Pract. 2011;27(8):53147.

21.Dean E. Physical therapy in the 21st century (Part I): toward practice informed by epidemiology and the crisis of lifestyle conditions. Physiother Theory Pract. 2009;25(5-6):330-53.

22. Dean E. Physical therapy in the 21 st century (Part II): evidence-based practice within the context of evidence-informed practice. Physiother Theory Pract. 2009;25(5-6):354-68.

23. Skinner EH, Haines KJ, Hayes K, Seller D, Toohey JC, Reeve JC et all. Future of specialised roles in allied health practice: who is responsible? Aust Health Rev. 2015;39(3):255-59.

24. [Internet] APTA Vision Sentence and Vision Statement for Physical Therapy 2020. Internet. Dostupno na: http://www.apta.org/Vision2020/. (Datum zadnjeg pristupa: 31.10.2018.) 


\title{
PHYSIOTHERAPY COMPETENCES IN THE MODERN HEALTHCARE SYSTEM
}

\author{
Dragan Mijatović ${ }^{1}$, Antonija Hrkać ${ }^{1}$, Mate Brekalo \\ ${ }^{1}$ Faculty of Health Studies, University of Mostar B\&H \\ ${ }^{2}$ The Faculty of Science and Education, University of Mostar, B\&H
}

\begin{abstract}
INTRODUCTION: Physiotherapists of the 21st century are healthcare professionals who have completed the study of physiotherapy and are trained and qualified to participate in patient assessment procedures, development and implementation of the therapeutic plan, and they play a major role in prevention and assessment of the effects of therapy.

OBJECTIVE: The objective of this study is to describe the competences of physiotherapists in the modern healthcare system and to reflect on the international standards and recommendations on the work of the same as well as the standards of the world and European confederation of physical therapy, WCPT and ERWCPT.

METHODS: We conducted searches of PubMed, EBSCO and Google Scholar databases by keywords over the past ten years and the emphasis was on articles concerned with professional competences of physiotherapists in the modern healthcare system.

RESULTS:The analysed articles reveal that the educational systems are still incapable of following a number of recommendations from WCPT and ERWCPT. The aim is to enable a physiotherapist to make an informed clinical judgement on whether the client or patient should be kept or referred to another professional concerned with one or more areas of specialty.
\end{abstract}

CONCLUSION: Identifying and evaluating competences of physiotherapists as well as of those that are absent is essential for successful work.

Key words: physiotherapy, professional competence, physiotherapy education, standards

\author{
Correspondence: \\ Dragan Mijatović \\ Email: mijatovicdragan@ymail.com
}

